function? Using a dominant-negative ERM molecule to mimic ERM inactivation, the authors showed that in the absence of ERM protein activity, the actin network close to the plasma membrane was disorganized, the rigidity of the T-cell membrane was reduced and $\mathrm{T}$ cells showed an enhanced capacity to form conjugates with APCs.

So, through activation of Rac1, Vav1 mediates inactivation of ERM proteins after TCR ligation, leading to morphological changes including relaxation of the cytoskeleton in $T$ cells. This enables them to interact with APCs more efficiently and so generate an effective immune response.

Jenny Buckland

(2) References and links ORIGINAL RESEARCH PAPER Faure, S. et al. ERM proteins regulate cytoskeleton relaxation promoting T cell-APC conjugation. Nature Immunol. 3, 272-279 (2004) FURTHER READING Vicente-Manzanares, M. \& Sánchez-Madrid, F. Role of the cytoskeleton during leukocyte responses. Nature Rev. Immunol. 3, 110-122 (2004)

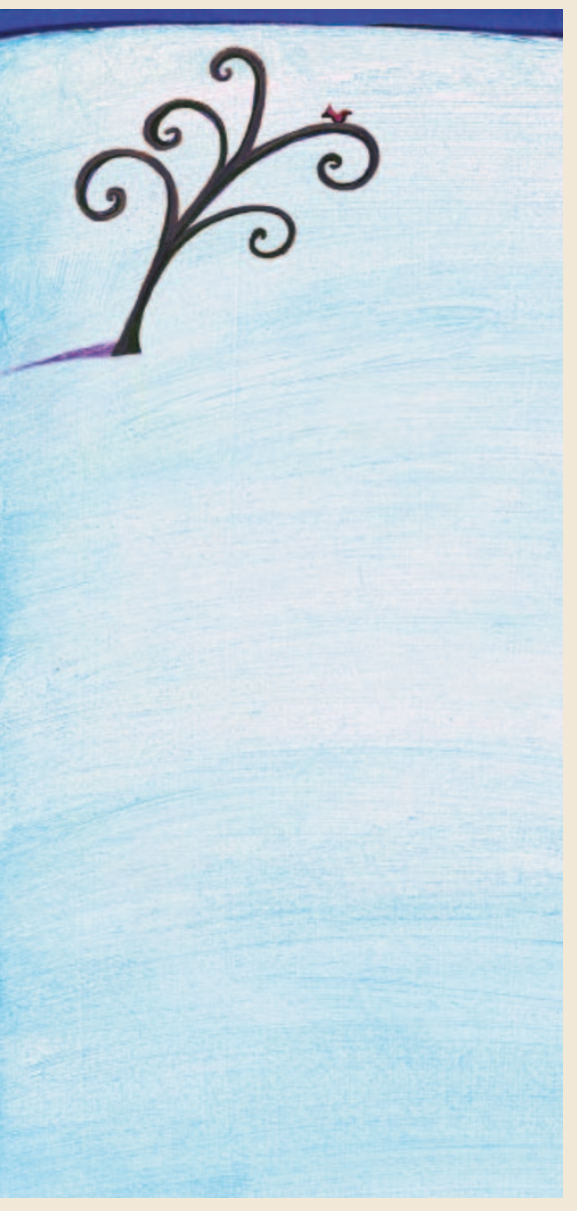

\title{
It's not what you do, it's the way that you do it
}

An antigen-specific autoreactive T-cell response per se does not cause autoimmune disease; rather, it is the quality of the T-cell response that counts. In the first example of its kind in humans, this study shows that non-diabetic individuals do mount responses against islet antigens, but that these responses are regulatory rather than inflammatory.

Previous studies of patients with type 1 diabetes have been hampered by the rarity of islet-specific $\mathrm{T}$ cells in peripheral blood, so Mark Peakman and colleagues have refined the cytokine enzyme-linked immunosorbent spot (ELISPOT) technique to develop a new highly sensitive assay for the detection of autoreactive T cells. First, the use of whole antigen preparations can have non-specific inhibitory or stimulatory effects on T cells, so the authors identified naturally processed and presented peptide epitopes (NPPEs) of the islet antigens insulinoma-associated 2 (IA-2) and pro-insulin by direct elution from HLA-DR4 molecules of antigen-pulsed antigen-presenting cells. Second, the sensitivity of the ELISPOT assay was increased by using a multiantigen, multiepitope panel, and by including an initial culture step of peripheral-blood mononuclear cells (PBMCs) in the presence of synthetic NPPEs but in the absence of cytokine-capture antibodies, to allow increased cell-cell interactions and signal amplification.

Using this technique, $72 \%$ of patients with type 1 diabetes had PBMCs that produced the pro-inflammatory cytokine interferon- $\gamma($ IFN- $\gamma$ ) in response to at least one of the IA- 2 and pro-insulin peptides, compared with only $7 \%$ of nondiabetic control subjects. However, the PBMCs from non-diabetic controls were not completely unresponsive to the islet antigens. $64 \%$ of them made an interleukin-10 (IL-10) response to IA-2 peptides compared with $29 \%$ of diabetic patients. Of the diabetic patients that did make an IL-10 response, almost all also made an IFN- $\gamma$ response, whereas control subjects produced IL-10 in the complete absence of IFN- $\gamma$. So, individuals with and without diabetes make qualitatively different responses to the same autoantigens. IL-10 is known to have immunosuppressive functions, so the T cells responding to islet antigens in healthy controls might have a regulatory role. Interestingly, those patients with diabetes who produced IL-10 and IFN- $\gamma$ in response to IA- 2 or pro-insulin tended to be older at diagnosis than patients who produced only IFN- $\gamma$, confirming the diseasemodifying effect of IL-10.

An assay that can distinguish between tolerant and autoimmune states by analysing peripheral blood will be of great use in monitoring treatment efficacy in immunointervention trials for type 1 diabetes. Given this first description of islet-antigen-specific regulatory $\mathrm{T}$ cells in humans, it will also be interesting to see if any treatments can specifically induce these T cells.

6) References and links

Kirsty Minton ORIGINAL RESEARCH PAPER Arif, S. et al. Autoreactive T cell responses show proinflammatory polarization in diabetes but a regulatory phenotype in health. J. Clin. Invest. 113, 451-463 (2004) FURTHER READING von Herrath, M. G. \& Harrison, L. C. Antigeninduced regulatory $T$ cells in autoimmunity. Nature Rev. Immunol. 3, 223-232 (2003) 